\title{
Valor Nutritivo de Alguns Ingredientes para o Robalo (Centropomus parallelus) ${ }^{1}$ Marcia Vanacor Barroso
, Josevane Carvalho Castro
Luiz Helmer $^{5}$
}

\begin{abstract}
RESUMO - Os robalos Centropomus são peixes que possuem alto valor comercial e grande importância econômica e social. Possuem potencial para aqüicultura, pois se adaptam ao confinamento e arraçoamento. O conhecimento dos requerimentos nutricionais dos robalos é básico para a elaboração de rações específicas. Para determinar a digestibilidade de alguns ingredientes utilizados em rações para peixes, trabalhou-se Centropomus parallelus, utilizando-se o farelo de soja, farelo de aveia e farelo de arroz, testados como ingredientes de rações que continham $0,5 \%$ de óxido crômico $\left(\mathrm{Cr}_{2} \mathrm{O}_{3}\right)$ como marcador externo. A metodologia experimental foi composta de quatro tanques cilíndrico-cônicos, com volume de $60 \mathrm{~L}$ e 10 peixes cada, conectados a dois filtros biológicos interligados com volume útil de $100 \mathrm{~L}$. O fundo dos tanques foi usado para coleta dos excrementos e as amostras foram armazenadas e, após, secas em estufa a $55,0^{\circ} \mathrm{C}$ para análises. Os valores de digestibilidade aparente da matéria seca, proteína bruta e energia bruta das rações foram, respectivamente: farelo de soja, 78,74\%, 90,96\%,82,66\%; farelo de aveia, 48,06\%, 81,10\%, 60,25\%; farelo de arroz, 59,34\%, 86,98\%, 69,06\% e da matéria seca digestível, proteína digestível e energia digestível dos alimentos: farelo de soja, 65,38\%, 36,04\%, $3497 \mathrm{kcal} / \mathrm{kg}$; aveia, 21,36\%, 9,15\%, 4197 kcal/kg; farelo de arroz, 46,41\%, 6,57\%, $3434 \mathrm{kcal}$.
\end{abstract}

Palavras-chave: aqüicultura, digestibilidade, nutrição, robalo

\section{Nutritive Value for Some Ingredients for Snook (Centropomus parallelus)}

\begin{abstract}
The snooks Centropomus parallelus are fishes with high commercial value and social and economic importance. They have potencial to be used in aquaculture, as they accept to be confined and to be fed with ration. The knowledge of the nutritional requeriments of the snook is basic to produce especific ration. Centropomus parallelus fed soybean meal, oat meal and rice meal, tested as ration ingredients with $0.5 \%$ to chromium oxide $\left(\mathrm{Cr}_{2} \mathrm{O}_{3}\right)$, as a external marker, were used to determine the digestibility of some ingredients used in fish ration. The experimental methodology was composed by four cylinder-conical tanks, with $60 \mathrm{~L}$ of volume each, with ten fishes, connected to two interchanged biological filter with $100 \mathrm{~L}$ of volume. The bottom of the tanks was used for the excrement collection, and the samples collected were frozen and, after, dried in stove at $55.0^{\circ} \mathrm{C}$ for analyses. The apparent digestibility values of dry matter, crude protein and gross energy in the ration were: soybean meal, 78.74, 90.96, and 82.66\%; oat, 48.06, 81.10\%, and 60.25\%; rice meal, $59.34,86.98$, and $69.06 \%$; dry matter digestibility, crude protein digestibility and gross energy digestibility of ingredients were: soybean meal, $65.38 \%, 36.04 \%, 3497 \mathrm{kcal} / \mathrm{kg}$; oat, $21.36 \%, 9.15 \%$, and $4197 \mathrm{kcal} / \mathrm{kg}$; rice meal, $46.41 \%, 6.57 \%$, and $3434 \mathrm{kcal} / \mathrm{kg}$.
\end{abstract}

Key Words: aquaculture, digestibility, nutrition, snook

\section{Introdução}

A aqüicultura é um dos setores de produção de alimentos em elevada expansão mundial, passando nas últimas décadas de modelos rudimentares de economia familiar para atividade empresarial, em muitos casos altamente tecnificada (New, 1998). Por outro lado, Benetti (1998) relata os recentes progressos da piscicultura marinha e descreve o uso do robalo em aqüicultura em fase de pesquisa, ou seja, já há controle de maturação, desova e larvicultura, porém as taxas de sobrevivência são ainda muito baixas.

Os robalos são peixes marinhos de águas costeiras que adentram os estuários e rios de água doce nas diferentes fases de seu ciclo de vida. Habitam, portanto, as principais bacias hidrográficas de sua área de ocorrência nos seus cursos inferiores (Gilmore et al., 1983; Alvarez-Lajonchere et al., 1982). Segundo Rivas (1986), são consideradas 12 espécies válidas, com distribuição geográfica nas Américas do Norte,

\footnotetext{
${ }^{1}$ Parte do trabalho de Dissertação de Mestrado da primeira autora, desenvolvida pelo Programa de Pós-Graduação em Ciências Biológicas da Universidade Federal do Espírito Santo - UFES/Bolsa de estudos da Empresa Brasileira de Pesquisa Agropecuária - EMBRAPA.

2 Pesquisadora do Instituto Capixaba de Pesquisa, Assistência Técnica e Extensão Rural - INCAPER - CRDR-Linhares Rod BR 101-Norte Km 151 - Linhares/ES - CEP: 29.900-970. E.mail: vanacor@incaper.es.gov.br

3 Professor Adjunto IV do Departamento de Zootecnia do Centro Ciências Agrárias da Universidade Federal do Espírito Santo. E.mail: jccastro@npd.ufes.br

4 Professora do Departamento de Zootecnia da UVV. E.mail: pieraoki@ig.com.br

5 Professor do Departamento de Ciências Biológicas da FAESA e IESESFA. E.mail: jlhelmer@escelsa.com.br
} 
Central e do Sul, sendo seis espécies no Pacífico e seis no Atlântico. Para a costa brasileira são citadas quatro espécies: Centropomus undecimalis, Centropomus parallelus, Centropomus ensiferus e Centropomus pectinatus (Figueiredo \& Menezes, 1985), sendo as que as duas primeiras são predominantes. Por possuírem alto valor comercial são intensamente capturados, o que consequentemente tem provocado redução dos estoques naturais destes peixes (Chavez, 1963; Rojas, 1975).

O hábito alimentar destes peixes foi descrito por Rojas (1975), Vasconcellos Filho et al. (1980) e Ramos-Porto \& Vasconcellos Filho (1978), que através do estudo do conteúdo estomacal identificaram a preferência alimentar por peixes, sem seleção de espécies, completando sua dieta com crustáceos, moluscos, ovos de peixes e insetos, classificando-o como carnívoro.

Os robalos têm despertado grande interesse para o cultivo comercial, pois se adaptam ao cativeiro e alimentação à base de ração (Cerqueira \& Macchiavello, 1994, Borba \& Cerqueira, 1998). Porém ainda estão em fase de pesquisa questões como densidade populacional, tempo de cultivo e alimentação adequada (Barroso, 2000).

Mendoza (1996) atribuiu o limitado êxito no cultivo intensivo de várias espécies de peixes marinhos ao escasso conhecimento do desenvolvimento morfológico e funcional do sistema digestório das larvas, assim como o desconhecimento das exigências nutricionais, particularmente a protéica.

Para elaboração de dietas comerciais específicas para grupos de peixes, necessita-se de informações quantitativas sobre as exigências de proteínas, ácidos graxos essenciais, vitaminas, minerais, energia e a digestibilidade dos ingredientes para otimizar as dietas e melhorar a eficiência de produção (Gatlin III, 1996).

Outro ponto importante na formulação de rações é a sua palatabilidade. Person-Le Ruyet \& Noël (1982) abordaram a necessidade de incrementar a palatabilidade das rações utilizando substâncias atrativas previamente testadas. Treviño Carrillo \& Celis Gutierrez (1996) ressaltaram que a palatabilidade é fator limitante para o uso da soja em rações para espécies de trutas e salmões.

Em investigação nutricional, a utilização do óxido crômico como marcador externo tem sido eficiente. Determinando-se a concentração do indicador no material fecal, a coleta de fezes mostra-se um método preciso para determinar a digestibilidade
(Austreng, 1978; D’abramo \& Castell, 1996; McGoogan \& Reigh, 1996).

Castro et al. (1998) relataram que o conhecimento da digestibilidade dos nutrientes e, particularmente, da energia metabolizável dos alimentos é indispensável para a formulação de rações que atendam as exigências nutricionais dos animais em cativeiro. Para robalos (Centropomus spp.) este conhecimento é muito restrito, não havendo dados disponíveis sobre a digestibilidade dos ingredientes utilizados nas rações e sua exigência nutricional.

Este trabalho foi conduzido com o objetivo de determinar os valores de matéria seca digestível, proteína digestível e energia digestível dos ingredientes usados em rações para robalos Centropomus parallelus, assim como o desempenho destes no crescimento dos peixes.

\section{Material e Métodos}

Foram realizados estudos preliminares com robalos selvagens da espécie Centropomus undecimalis em sistema aberto. Houve dificuldade na alimentação destes peixes com ração e grande variação na temperatura da água, gerando estresse, doenças e mortalidade. Em função disso, os experimentos foram realizados com robalos Centropomus parallelus provenientes de desova induzida no laboratório da Universidade Federal de Santa Catarina, pois se alimentam vorazmente de ração. Visando variações mínimas na qualidade de água a condução dos trabalhos deu-se em sistema fechado.

Os experimentos foram conduzidos no período de janeiro a maio de 2000 no Laboratório de Aqüicultura da Universidade Federal do Espírito Santo, Campus de Goiabeiras, Vitória, ES.

Foram utilizados quatro tanques de experimentação de fibra de vidro e formato cilíndrico-cônico (denominados unidade experimental), volume de $60 \mathrm{~L}$, densidade de 10 peixes/tanque, em água doce e sistema fechado, tampados com plástico transparente, a fim de evitar fuga dos peixes. Os tanques foram conectados a dois filtros biológicos interligados, contendo água doce com volume útil de $100 \mathrm{~L}$, utilizandose algas calcárias secas como substrato para bactérias nitrificantes filtradoras de amônia.

O abastecimento de água foi feito através de tubo PVC, onde a entrada de água ocorria a $50 \mathrm{~cm}$ da superfície. A drenagem de água deu-se pela superfície dos tanques, que estavam conectados a uma calha

R. Bras. Zootec., v.31, n.6, p.2157-2164, 2002 
e esta ao filtro 1. A água passava pelo substrato, abastecendo o filtro 2 pela drenagem. Na superfície do filtro 2 acoplou-se uma bomba submersível, com vazão de $636 \mathrm{~L} / \mathrm{h}$, que conduzia a água por intermédio do substrato filtrante, devolvendo-a aos tanques experimentais (Figura 1).

Os filtros biológicos foram maturados por quinze dias antes da introdução dos robalos na unidade experimental, testados através de um kit de análise de amônia, com escala de intervalo de 0,2 mg/L.

Controlou-se a vazão de água nos tanques experimentais através de registros, mantendo-se em $3 \mathrm{~mL} / \mathrm{s}$, totalizando uma vazão aproximada de quatro vezes o volume de cada tanque a cada 24 horas.

Devido ao fato de abastecerem-se e drenarem-se os tanques a meia água e pela superfície, respectivamente, o fundo destes foi destinado exclusivamente para a coleta de fezes e a eliminação do excesso de ração. Para coleta de fezes foram utilizados quatro beckers plásticos com volume de $1 \mathrm{~L}$ cada, devidamente numerados, sendo um para cada tanque.

$\mathrm{O}$ ensaio de digestibilidade foi feito com três ingredientes: farelo de soja, farelo de aveia e farelo de arroz. Foram formuladas quatro dietas, sendo uma basal, elaborada com farinha de peixe e três experimentais com substituição parcial da primeira, por um dos ingredientes testados. O farelo de aveia e o farelo de arroz foram usados em substituição a $30 \%$ da matéria natural da dieta basal e o farelo de soja em $20 \%$. A dieta basal foi adaptada da fórmula para

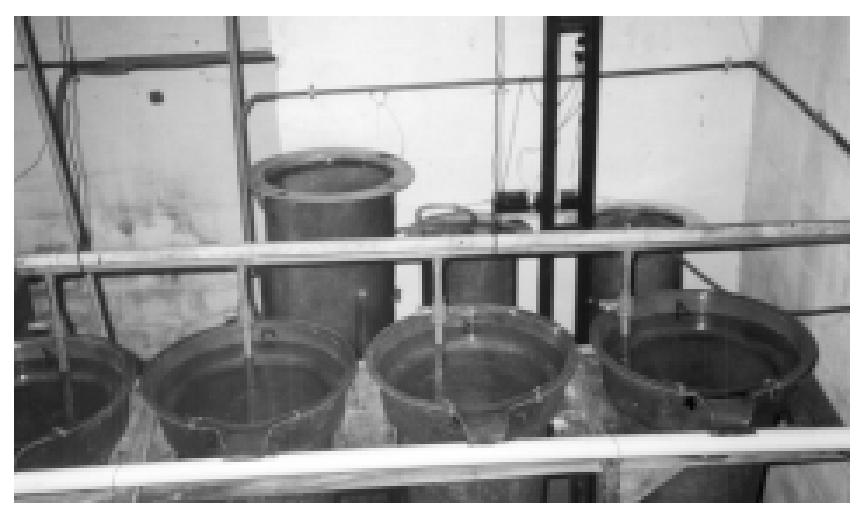

Figura 1 - Vista geral da unidade experimental contendo quatro tanques experimentais acoplados a dois filtros biológicos interligados.

Figure 1 - General view of experimental unit four experimental tanks conected to two interchanged biological filter. peixes marinhos, fornecida por Alvarez- Lajonchere (1998) e a sua composição e das dietas experimentais estão na Tabela 1 . Acresceu-se às rações $0,5 \%$ de óxido crômico $\left(\mathrm{Cr}_{2} \mathrm{O}_{3}\right)$, como marcador externo.

Oexperimento foi iniciado com $30 \%$ de substituição da dieta basal para todos os tratamentos, porém a dieta com farelo de soja apresentou baixa palatabilidade. Os peixes famintos eram atraídos pela dieta quando a mesma era lançada na água, mas ao aproximarem-se, recuavam, ou quando ingeriam-na, expeliam imediatamente. Ao reduzir-se para $20 \%$ o teor de farelo de soja, esta foi mais consumida.

Tabela 1 - Composição percentual das dietas experimentais

Table 1 - Percentage composition of the experimental diets

\begin{tabular}{|c|c|c|c|c|}
\hline \multirow[t]{2}{*}{$\begin{array}{l}\text { Ingrediente } \\
\text { Ingredient }\end{array}$} & \multicolumn{4}{|c|}{$\begin{array}{c}\text { Dieta }(\%) \\
\text { Diet }\end{array}$} \\
\hline & $\mathrm{RB}^{1}$ & $\mathrm{RS}^{2}$ & $\mathrm{RA}^{3}$ & $\mathrm{Rfa}^{4}$ \\
\hline $\begin{array}{l}\text { Farinha de peixe } \\
\text { Fish meal }\end{array}$ & 65,0 & 45,0 & 35,0 & 35,0 \\
\hline $\begin{array}{l}\text { Farelo de soja } \\
\text { Soybean meal }\end{array}$ & - & 20,0 & - & - \\
\hline $\begin{array}{l}\text { Farelo de aveia } \\
\text { Oat meal }\end{array}$ & - & - & 30,0 & - \\
\hline $\begin{array}{l}\text { Farelo de arroz } \\
\text { Rice meal }\end{array}$ & - & - & - & 30,0 \\
\hline Fubá de milho pré-cozido & 10,0 & 10,0 & 10,0 & 10,0 \\
\hline $\begin{array}{l}\text { Cooked corn gluten meal } \\
\text { Óleo de fígado de peroá } \\
\text { (Balistes vetula) } \\
\text { Marine fish liver oil }\end{array}$ & 10,0 & 10,0 & 10,0 & 10,0 \\
\hline $\begin{array}{l}\text { Alginato de sódio } \\
\text { Sodium alginate }\end{array}$ & 6,5 & 6,5 & 6,5 & 6,5 \\
\hline $\begin{array}{l}\text { Gelatina } \\
\text { Gelatin }\end{array}$ & 5,0 & 5,0 & 5,0 & 5,0 \\
\hline $\begin{array}{l}\text { Suplemento vitamínico } \\
\text { Vitamin premix }\end{array}$ & 1,0 & 1,0 & 1,0 & 1,0 \\
\hline $\begin{array}{l}\text { Suplemento mineral }{ }^{6} \\
\text { Mineral premix }\end{array}$ & 1,0 & 1,0 & 1,0 & 1,0 \\
\hline $\begin{array}{l}\text { VitaminaC } \\
\text { Vitamin } C\end{array}$ & 1,0 & 1,0 & 1,0 & 1,0 \\
\hline $\begin{array}{l}\text { Óxido crômico } \\
\text { Chromium oxide }\end{array}$ & 0,5 & 0,5 & 0,5 & 0,5 \\
\hline Total & 100,0 & 100,0 & 100,0 & 100,0 \\
\hline
\end{tabular}

${ }_{1}$ Dieta basal (basal ration).

2 Tratamento com farelo de soja (soybean meal treatment).

3 Tratamento com farelo de aveia (oat meal treatment).

${ }^{4}$ Tratamento com farelo de arroz (rice meal treatment).

${ }^{5}$ Suplemento vitamínico (Vitamin premix): Vit. A - $600.000 \mathrm{UI}$; Vit. $D_{3}-100.000$ UI; Vit. E - 6.000 Ul; Vit. K-1,2 g; Vit. $B_{12}-2,4 \mathrm{mg}$; Tiamina (Tiamin); Vit. B $-2,4 \mathrm{~g}$; Riboflavina (Riboflavin); Vit. $\mathrm{B}_{2}-2,4 \mathrm{~g}$; Piridoxina (Piridoxin) (Vit. $\left.\mathrm{B}_{6}\right)-2,4 \mathrm{~g}$; Biotina (Biotin) $0,024 \mathrm{~g}$; Ácido fólico (Folic acid) - 0,6 g; Ácido pantotênico (Pantotenic acid) - 6,0 g; Niacina (Niacin) - 12 g; Cloreto de Colina (Coline cloride) $-54,0 \mathrm{~g}$.

${ }^{6}$ Suplemento mineral (mineral premix): $\mathrm{Fe}-5,0 \mathrm{~g}$; $\mathrm{Cu}-0,3 \mathrm{~g}$; $\mathrm{Mn}-2,0 \mathrm{~g} ; \mathrm{Co}-1,0 \mathrm{~g} ; \mathrm{I}-10,0 \mathrm{~g} ; \mathrm{Se}-10,0 \mathrm{~g}$ e Zn - 3,0 g.

R. Bras. Zootec., v.31, n.6, p.2157-2164, 2002 
Para o preparo das dietas os ingredientes foram pesados em balança digital, capacidade $1500 \mathrm{~g} \mathrm{x} 0,1 \mathrm{~g}$, misturados, triturados e peneirados em malha de 0,5 $\mathrm{mm}$, sem os aglutinantes (gelatina e alginato de sódio). Adicionou-se água quente com a gelatina previamente dissolvida na mesma. Após bem homogeneizada, acresceu-se o alginato de sódio para aglutinação final, minimizando o processo de lixiviação dos peletes. As misturas foram peletizadas com três mm de diâmetro.

As análises de matéria seca, proteína bruta e energia bruta foram realizadas conforme descrita por Silva (1990). A matéria seca e proteína bruta foram determinadas no Laboratório de Nutrição Animal do Centro Ciências Agrárias da Universidade Federal do Espírito Santo (CCA-UFES) e a energia bruta no Laboratório de Nutrição da UNESP - Jaboticabal, utilizando-se bomba calorimétrica.

Os cálculos de proteína e energia digestível aparente, para as rações basal e experimentais foram efetuadas a partir dos níveis de óxido crômico nas rações e nas fezes, sendo a seguir estimados os coeficientes de digestibilidade aparente para cada ingrediente testado.

Para os cálculos do coeficiente de digestibilidade aparente (CDA), foram utilizadas as seguintes fórmulas:

CDA da dieta referência $(\%)=100-\left(100 \times \%\right.$ nutrientes fezes $\times \% \mathrm{Cr}_{2} \mathrm{O}_{3}$ dieta $)$ $\% \overline{\text { nutrientes da dieta } \% \mathrm{Cr}_{2} \mathrm{O}_{3} \text { fezes }}$

CDA ingrediente $(\%)=\mathrm{CDA}$ basal $-(\mathrm{CDA}$ experimental $-\mathrm{CDA}$ basal $)$ $\overline{\mathrm{g} \text { alimento teste/g dieta basal }}$

\section{Resultados e Discussão}

Qualidade de água, crescimento e conversão alimentar

A temperatura da água manteve-se entre $28,0 \pm$ $1^{\circ} \mathrm{C}$, compatíveis com os resultados encontrados por Borba \& Cerqueira (1998) e pH entre 7,0 e 7,2.

Tucker et al. (1988) relataram que juvenis de barramundi, assim como o robalo Centropomus undecimalis, precisam de temperatura mínima de $25^{\circ} \mathrm{C}$, sendo que o melhor crescimento se dá em temperaturas em torno de $27^{\circ} \mathrm{C}$, bem próxima àquela dos experimentos. Relataram também que crescimento e conversão alimentar são similares em água doce ou salgada.

Os tratamentos apresentaram boa qualidade da água para cultivo de peixes (D'Abramo \& Castell, 1996), que pode ser evidenciada com uma taxa de

R. Bras. Zootec., v.31, n.6, p.2157-2164, 2002
Tabela 2 - Quantidade total de alimento consumido $(F)$, taxa de alimentação média diária ( $f$ ), fator de conversão alimentar (CA), biomassa adquirida (B) e sobrevivência (S) de Centropomus parallelus

Table 2 - Total feed intake ( $F)$, average daily feed rate (f), feed conversion (CA), biomass $(B)$ and survival rate $(S)$ of Centropomus parallelus

\begin{tabular}{|c|c|c|c|c|c|}
\hline $\begin{array}{l}\text { Dieta } \\
\text { Diet }\end{array}$ & $F(g)$ & $\mathrm{f}(\%)$ & CA & $\mathrm{B}(\mathrm{g})$ & $\mathrm{S}(\%)$ \\
\hline $\begin{array}{l}\text { Basal } \\
\text { Basal }\end{array}$ & 56,2 & 1,8 & 1,05 & 53,5 & 100 \\
\hline $\begin{array}{l}\text { Farelo de soja } \\
\text { Soybean meal }\end{array}$ & 64,8 & 2,5 & 1,13 & 57,1 & 100 \\
\hline $\begin{array}{l}\text { Farelo de aveia } \\
\text { Oat meal }\end{array}$ & 47,3 & 1,5 & 1,61 & 29,4 & 100 \\
\hline $\begin{array}{l}\text { Farelo de arroz } \\
\text { Rice meal }\end{array}$ & 50,1 & 1,7 & 1,88 & 26,6 & 100 \\
\hline
\end{tabular}

sobrevivência de $100 \%$ em todos os tratamentos e em todas as repetições (Tabela 2).

A quantidade total de alimento consumido (F), taxa de alimentação média diária (f), conversão alimentar (CA) e biomassa adquirida (B) na dieta basal e nos tratamentos com farelo de soja, farelo de aveia e farelo de arroz estão na Tabela 2 .

Analisando-se os valores de incremento de peso nos indivíduos estudados, constata-se que a ração com farelo de soja apresentou resultado superior às demais $(58,7 \%)$, superando em $12,6 \%$ a ração basal. Os tratamentos com aveia e farelo de arroz, apresentaram percentuais bem mais baixos (24,6 e 23,9\% respectivamente). Os resultados detalhados encontram-se na Tabela 3.

Em relação ao comprimento dos peixes, a dieta basal proporcionou o melhor desempenho, seguida pelas rações com farelo de soja, farelo de aveia e farelo de arroz (Tabela 3).

As melhores respostas, em crescimento, foram obtidas com a ração basal e o tratamento com farelo de soja, rações com alimentos protéicos. Os tratamentos aveia e farelo de arroz, rações com alimentos energéticos (maior quantidade de carboidratos) obtiveram pior desempenho em crescimento e maior conversão alimentar. Digestibilidade aparente

A composição nutricional dos ingredientes utilizados nas dietas experimentais está na Tabela 4. Os valores foram discutidos em função dos valores obtidos para cada ingrediente separadamente.

Considerando os valores do coeficiente de digestibilidade da matéria seca e da proteína bruta das 
Tabela 3 - Peso (W) e comprimento (L) médios inicial e final, percentagem de incremento de peso (IW) e crescimento (IL) obtidos nas dietas experimentais para Centropomus parallelus

Table 3 - Average weight (W) and lenght (L), weigt increase percentage (WI) and lenght increase percentage (LI) of the experimental diets to Centropomus parallelus

\begin{tabular}{|c|c|c|c|c|c|c|}
\hline \multirow{2}{*}{$\begin{array}{l}\text { Dieta } \\
\text { Diet }\end{array}$} & \multicolumn{2}{|c|}{ W (g) } & \multirow[t]{2}{*}{ IW (\%) } & \multicolumn{2}{|c|}{ IL (cm) } & \multirow[t]{2}{*}{$\mathrm{L}(\%)$} \\
\hline & $\begin{array}{c}\text { Inicial } \\
\text { Beginning }\end{array}$ & $\begin{array}{l}\text { Final } \\
\text { Finish }\end{array}$ & & $\begin{array}{c}\text { Inicial } \\
\text { Beginning }\end{array}$ & $\begin{array}{l}\text { Final } \\
\text { Finish }\end{array}$ & \\
\hline $\begin{array}{l}\text { Basal } \\
\text { Basal }\end{array}$ & 11,60 & 16,95 & 46,1 & 10,79 & 11,79 & 9,3 \\
\hline $\begin{array}{l}\text { Farelo de soja } \\
\text { Soybean meal }\end{array}$ & 9,73 & 15,44 & 58,7 & 10,44 & 11,30 & 8,2 \\
\hline $\begin{array}{l}\text { Farelo de aveia } \\
\text { Oat meal }\end{array}$ & 11,97 & 14,91 & 24,6 & 10,95 & 11,59 & 5,8 \\
\hline $\begin{array}{l}\text { Farelo de arroz } \\
\text { Rice meal }\end{array}$ & 11,11 & 13,77 & 23,9 & 10,70 & 11,32 & 5,8 \\
\hline
\end{tabular}

Tabela 4 - Composição da matéria seca (MS), Proteína bruta (PB), energia bruta (EB), proteína digestível (PD) e energia digestível (ED) dos ingredientes utilizados nas dietas experimentais na matéria natural (MN) e na matéria seca (MS)

Table 4 - Dry matter composition (DM), crude protein (CP), gross energy (GE), digestible protein (DP) and digestible energy (DE) of the ingredients, as as fed (NM) and dry matter (DM) basis

\begin{tabular}{|c|c|c|c|c|c|c|c|c|c|}
\hline \multirow[t]{3}{*}{$\begin{array}{l}\text { Ingrediente } \\
\text { Ingredient }\end{array}$} & \multirow[t]{3}{*}{$\begin{array}{l}M S(\%) \\
D M(\%)\end{array}$} & \multicolumn{2}{|c|}{$\begin{array}{l}\mathrm{PB}(\%) \\
C P(\%)\end{array}$} & \multicolumn{2}{|c|}{$\begin{array}{l}\mathrm{EB}(\mathrm{kcal} / \mathrm{kg}) \\
G E(k c a l / k g)\end{array}$} & \multicolumn{2}{|c|}{$\begin{array}{l}\mathrm{PD}(\%) \\
D P(\%)\end{array}$} & \multicolumn{2}{|c|}{$\begin{array}{l}\mathrm{ED}(\%) \\
D E(\%)\end{array}$} \\
\hline & & $\mathrm{MN}$ & MS & $\mathrm{MN}$ & MS & $\mathrm{MN}$ & MS & $\mathrm{MN}$ & MS \\
\hline & & $N M$ & $D M$ & $N M$ & $D M$ & $N M$ & $D M$ & $N M$ & $D M$ \\
\hline Farelo soja & 83,96 & 45,72 & 38,38 & 4218 & 3541 & 36,04 & 30,25 & 3497 & 2936 \\
\hline Soybean meal & 8047 & 1160 & 1038 & 4305 & 3852 & 015 & 810 & 4107 & 3755 \\
\hline Oat meal & & & & & & & & & \\
\hline $\begin{array}{l}\text { Farelo arroz } \\
\text { Rice meal }\end{array}$ & 87,59 & 8,25 & 7,23 & 3774 & 3306 & 6,57 & 5,75 & 3434 & 3008 \\
\hline
\end{tabular}

dietas basal e experimentais, verificou-se que a dieta com farelo de soja foi a que obteve maior digestibilidade e a ração com farelo de aveia, a menor.

Os valores referentes à proteína digestível (PD) e energia digestível (ED) das dietas encontram-se na Tabela 5. A proteína digestível e a energia digestível da dieta com farelo de soja foram, respectivamente $37,33 \%$ e $4132 \mathrm{kcal} / \mathrm{kg}$. Estes resultados são compatíveis e superiores em termos energéticos aos obtidos por Cavalheiro \& Pereira (1998), que trabalharam com robalos Centropomus parallelus, e obtiveram $3200 \mathrm{kcal} / \mathrm{kg}$ para dietas contendo 35,00 e 40,00\% de proteína.

As rações com farelo de aveia e farelo de arroz apresentaram valores baixos de proteína digestível, $27,33 \%$ e $27,38 \%$ respectivamente. Cowey et al. (1970) trabalhando com o linguado (Pleuronectes platessa), mostraram que há significativo aumento no crescimento absoluto, quando há aumento no nível de proteína na dieta. O robalo Centropomus parallelus, por ser carnívoro, necessita de índices protéicos em torno de 45,0\% (Cavalheiro \& Pereira,1998).

Entre os ingredientes vegetais utilizados em rações, a soja tem-se destacado devido à sua composição química, perfil de aminoácidos mais favoráveis e alta disponibilidade, a um custo mais baixo do que a farinha de peixe. A soja crua porém, contém diversos fatores anti-nutricionais que afetam o crescimento $\mathrm{e}$ a saúde dos peixes. No entanto, existem métodos de tratamento com calor (tostar, extrusar e peletizar) que têm sido usados para desativar ou eliminar estes fatores, melhorando assim o valor nutritivo da soja. $\mathrm{O}$ farelo de soja proveniente da soja descascada cujo óleo foi extraído com solventes possui $49,0 \%$ de proteína bruta da qual aproximadamente $85,0 \%$ é digestível para bagre de canal, truta arco-íris e tilápia (Trevinõ Carrilo \& Celis Gutierrez, 1996).

Os valores de coeficiente de digestibilidade aparente da matéria seca (CDAMS), matéria seca digestível 
Tabela 5 - Fator de digestibilidade (FI), coeficiente de digestibilidade aparente da matéria seca (CDAMS), da proteína bruta (CDAPB) e da energia bruta (CDAEB), proteína digestível (PD) e energia digestível (ED) das dietas para robalos Centropomus parallelus

Table 5 - Digestibility factor (DF), apparent digestibility coefficient of dry matter (ADCDM), crude protein (ADCCP) and gross energy (ADCGE), digestible protein $(D P)$ and digestible energy (DE) of the experimental diets fed to Centropomus parallelus

\begin{tabular}{|c|c|c|c|c|c|c|}
\hline $\begin{array}{l}\text { Dieta } \\
\text { Diet }\end{array}$ & $\begin{array}{l}\text { FI }(\%) \\
D F A D\end{array}$ & $\begin{array}{c}\text { CDAMS }(\%) \\
C D M A\end{array}$ & $\begin{array}{c}\mathrm{CDAPB}(\%) \\
D C G P A\end{array}$ & $\begin{array}{c}\mathrm{CDAEB}(\%) \\
D C G E\end{array}$ & $\begin{array}{c}\mathrm{PD}(\%) \\
D P\end{array}$ & $\begin{array}{c}\mathrm{ED}(\mathrm{kcal} / \mathrm{kg}) \\
D E\end{array}$ \\
\hline $\begin{array}{l}\text { Basal } \\
\text { Basal }\end{array}$ & 21,80 & 78,20 & 88,30 & 82,82 & 40,05 & 4161 \\
\hline $\begin{array}{l}\text { Farelo de soja } \\
\text { Soybean meal }\end{array}$ & 21,26 & 78,74 & 90,96 & 82,66 & 37,33 & 4132 \\
\hline $\begin{array}{l}\text { Farelo de aveia } \\
\text { Oat meal }\end{array}$ & 51,94 & 48,06 & 81,10 & 60,25 & 27,33 & 2868 \\
\hline $\begin{array}{l}\text { Farelo de arroz } \\
\text { Rice meal }\end{array}$ & 40,66 & 59,34 & 86,98 & 69,06 & 27,38 & 3244 \\
\hline
\end{tabular}

Tabela 6 - Coeficiente de digestibilidade aparente da matéria seca (CDAMS), matéria seca digestível (MSD), proteína digestível (PD) e energia digestível (ED) dos ingredientes para robalos Centropomus parallelus

Table 6 - Apparent digestibility coefficient of dry matter (ADCDM), digestible dry matter (DDM), digestible protein $(D P)$ and digestible energy (DE) of ingredients of the experimental diets fed to Centropomus parallelus

\begin{tabular}{|c|c|c|c|c|}
\hline $\begin{array}{l}\text { Ingrediente } \\
\text { Ingredient }\end{array}$ & $\begin{array}{c}\text { CDAMS }(\%) \\
A D C D M\end{array}$ & $\begin{array}{c}\mathrm{MSD}(\%) \\
D D M\end{array}$ & $\begin{array}{c}\mathrm{PD}(\%) \\
D P \\
\end{array}$ & $\begin{array}{c}\mathrm{ED}(\mathrm{kcal} / \mathrm{kg}) \\
D E\end{array}$ \\
\hline Farelo de soja & 77,88 & 65,38 & 36,04 & 3497 \\
\hline $\begin{array}{l}\text { Soybean meal } \\
\text { Farelo de aveia } \\
\text { Oat meal }\end{array}$ & 23,87 & 21,36 & 9,15 & 4197 \\
\hline $\begin{array}{l}\text { Farelo de arroz } \\
\text { Rice meal }\end{array}$ & 53,05 & 46,41 & 6,57 & 3434 \\
\hline
\end{tabular}

(MSD), proteína digestível (PD) e energia digestível (ED) dos ingredientes encontram-se na Tabela 6.

Foi observado que a palatabilidade parece ser um fator limitante na utilização do farelo de soja em dietas para o robalo (Centropomus parallelus), pois os peixes famintos abocanhavam a dieta e imediatamente expeliam-na, o que causou perda de peso nos peixes. A utilização do farelo de soja somente resultou em ingestão satisfatória quando o teor do mesmo na dieta baixou de 30 para $20 \%$, sendo então a dieta mais consumida (Tabela 2).

Obteve-se maior valor de proteína digestível para o farelo de soja $(36,04 \%)$, seguido pelo farelo de aveia $(9,15 \%)$ e farelo de arroz $(6,57 \%)$. O alimento com maior energia digestível foi o farelo de aveia (4197 kcal $/ \mathrm{kg})$, seguido do farelo de soja $(3497 \mathrm{kcal} / \mathrm{kg})$ e, por último, o farelo de arroz (3434 kcal/kg).

\section{Conclusões}

Nos experimentos preliminares observou-se a suscetibilidade dos robalos ao estresse e consequentemente, a doenças.

Neste experimento, o tratamento com farelo de soja, utilizando $20 \%$ de farelo de soja em substituição à farinha de peixe, resultou em ganho de peso superior até mesmo à ração basal, contendo $65 \%$ de farinha de peixe.

Os valores de digestibilidade aparente de matéria seca, da proteína bruta e da energia bruta das rações, foram respectivamente: farelo de soja, $78,74 \%$, 
$90,96 \%, 82,66 \%$; aveia, $48,06 \%, 81,10 \%, 60,25 \%$; farelo de arroz, 59,34\%, 86,98\%, 69,06\%.

Foram encontrados os valores de matéria seca digestível, proteína digestível e energia digestível, respectivamente, para os alimentos: farelo de soja, $65,38 \%$, $36,04 \%, 3497 \mathrm{kcal} / \mathrm{kg}$; aveia, 21,36\%, 9,15\%, 4197 $\mathrm{kcal} / \mathrm{kg}$; farelo de arroz, $46,41 \%, 6,57 \%, 3434 \mathrm{kcal} / \mathrm{kg}$.

\section{Agradecimento}

Ao médico veterinário e piscicultor Paulo Perim, por ceder os robalos utilizados nos experimentos; ao Prof. Leoncínio José Gobo da Escola Agrotécnica Federal de Alegre pelo empréstimo dos tanques utilizados para montagem da unidade experimental; $\mathrm{D}^{\text {ra }}$ Silvia Pastore da Agribrands Purina do Brasil Ltda, pelo fornecimento dos premix vitamínico e mineral utilizados na formulação das rações; Geraldo Bernardino e Osmar Cantelmo do CEPTA/IBAMA, pela realização das análises de óxido de crômio; $\mathrm{D}^{\text {ra }}$ Marta Verardino de Stefani, do Laboratório de Nutrição da UNESP de Jaboticabal, pelas análises de energia; e EMBRAPA, pela bolsa de estudos.

\section{Literatura Citada}

ALVAREZ-LAJONCHERE, L.; HERNÁNDEZ MOLEJÓN, O.G. Reprodución e larvicultura de peces marinos. Recife: Aqüicultura Brasil'98, 1998. 110p.

ALVAREZ-LAJONCHERE, L.; BÁEZ HIDALGO, M.; GOTERA, G. Estudio de la biologia pesquera del robalo de ley, Centropomus undecimalis (Bloch) (Pisces, Centropomidae) en Tunas de Zaza, Cuba. Revista Investigaciones Marinas, v.3, n.1, p.159-200, 1982.

AUSTRENG, E. Digestibility determination in fish using chromic oxide marking and analysis of contents from different segments of gastrointestinal tract. Aquaculture, v.13, p.265-272, 1978.

BARROSO, M.V. Valor nutritivo de alguns alimentos para o robalo Centropomus parallelus Poey, 1860. Vitória: Universidade Federal do Espírito Santo, 2000. 44p. Dissertação (Mestrado em Ciências Biológicas - Biologia Animal) Universidade Federal do Espírito Santo, 2000.

BENETTI, D.D. Recent Progress in Marine Fish Aquaculture. In: CONGRESSO SUL-AMERICANO DE AQÜICULTURA, 1.; SIMPÓSIO BRASILEIRO DE AQÜICULTURA, 10., 1998, Recife. Anais... Recife: ABRAq, 1998. v.1, p.183-195.

BORBA, M. R., CERQUEIRA, V. R. 1998. Atrativos sintéticos na adaptação da larva do robalo (Centropomus parallelus) ao alimento formulado. In: CONGRESSO SUL-AMERICANO DE AQÜICULTURA, 1; SIMPÓSIO BRASILEIRO DE AQÜICULTURA, 10, 1998, Recife. Anais... Recife: ABRAq, 1998. v.2, p.117-123.

CASTRO, J.C.; LIMA, S.L.; DONZELE, J.L. et al. Energia metabolizável de alguns alimentos usados em rações de rãs. Revista Brasileira de Zootecnia, v.27, n.6, p.1051-1056, 1998.
CAVAlHEIRO, J. M.O.; PEREIRA, J.A. Efeito de diferentes níveis de proteína e energia em dietas no crescimento do robalo, Centropomus parallelus (Poey, 1860) em água doce. In: CONGRESSO SUL-AMERICANO DE AQÜICULTURA, 1; SIMPÓSIO BRASILEIRO DE AQÜICULTURA, 10., 1998, Recife. Anais... Recife: ABRAq, 1998. v.2, p.35-39.

CERQUEIRA, V.R.; MACHIAVELLO, J.A.G. Comparação do crescimento de juvenis do robalo (Centropomus undecimalis) alimentados com uma dieta experimental e uma dieta comercial para truta. In: SIMPÓSIO BRASILEIRO DE AQÜICULTURA, 7; ENCONTRO BRASILEIRO DE PATOLOGIA DE ORGANISMOS AQUÁTICOS, 3., 1994, Peruíbe, SP. Anais... Peruíbe: 1994.

CHÁVEZ, H. Contribución al conocimiento de la biologia de los robalos, chucumite y constantino (Centropomus Spp.) dela estado de Verácruz. (pisc. Centrop.) Ciência, v.22, n.5, p.141-161, 1963.

CHO, C.Y.; COWEY, C.B.; WATANABE, T. Finfish nutrition in Asia - Methodological apbroaches to research and development. Otawa: IDRC. 1985. 154 p.

COWEY, C.B.; ADRON, J.W.; BLAIR A. et al. The growth of O-group plaice on artificial diets containing different levels of protein. Helgoländer Wiss. Meeresunters, v.20, p.602$609,1970$.

D’ABRAMO, L.R.; CASTELL, J.D. Metodología para la investigación nutricional, In: MENDOZA, CRUZ-SUÁREZ Y RICQUE (Eds.). Simposium Internacional de Nutrición Acuícola, Memórias... Monterrey: 1996. p.103-121.

FIGUEIREDO, J.L.; MENEZES, A. Manual de peixes marinhos do sudeste do Brasil. v. Teleostei (4). Museu de Zoología da USP, 1985. 105p.

GATLIN, D. M. III. Nutrición y alimentación de la curvina y el híbrido de lobina, In: MENDOZA, CRUZ-SUÁREZ Y RICQUE (Eds.). Simposium Internacional de Nutrición Acuícola, 2., 1994, Monterrey. Memórias... Monterrey: 1996. p.123-128.

GILMORE, R.G.; DONOHOE, J.; COOKE, D.W. Observations on the distribuition and biology of east-central Florida populations of the common snook, Centropomus undecimalis (Bloch). Florida Science, v.46, n.3/4, p.313-336, 1983.

McGOOGAN, B.B.; REIGH, R.C. Apparent digestibility of select ingredients in red drum (Scianops ocellatus) diets. Aquaculture, v.141, p.233-244, 1996.

MENDOZA, R.A. Utilización de métodos imunológicos en el estudio de la nutrición de los organismos aquáticos, In: MENDOZA, CRUZ-SUÁREZ Y RICQUE (Eds.). Simposium Internacional de Nutrición Acuícola, 2., 1994, Monterrey. Memórias... Monterrey: 1996. p.129-156.

NEW, M. Global aquaculture: current trends and challenges for the $21^{\text {st }}$ century. In: CONGRESSO SUL-AMERICANO DE AQÜICULTURA, 1., SIMPÓSIO BRASILEIRO DE AQÜICUlTURA, 10., 1998, Recife. Anais... Recife: ABRAq, 1998. v.1. p-58.

PERSON-LE RUYET, J.; NOËL, T. Effects of moist pelleted foods on the growth of hatchery turbot (Scophthalmus maximus) juvenis. Journal of World Mariculture Society, v.13, p.237-245, 1982.

RAMOS-PORTO, N.; VASCONCELOS FILHO, A.L. Estudo da disponibilidade de alimentos para os peixes centropomídeos da Região de Itamaracá (Pernambuco - Brasil). In: SIMPÓSIO BRASILEIRO DE AQÜICULTURA, 1., 1978, Recife. Anais... Rio de Janeiro: Academia Brasileira de Ciências, 1978. p.185-192.

R. Bras. Zootec., v.31, n.6, p.2157-2164, 2002 
RIVAS, L.R. Systematic review of the perciform fishes of the genus Centropomus.Copeia, v.3, p.579-611, 1986.

ROJAS, J.C. Contribucion al conecimiento de la biologia de los robalos Centropomus undecimalis e C. poeyi en la Laguna de Terminos, Campeche, Mexico. Boletim do Instituto Oceanográfico Universidad de Oriente, v.14, n.1, p.51-70, 1975.

SILVA, D.J. Análise de alimentos (métodos químicos e biológicos). Viçosa, MG: Universidade Federal de Viçosa, 1990. $165 \mathrm{p}$.

TREVIÑO CARRILLO, M.C.L.M.; CELIS GUTIERREZ, M.V.Z.A. Uso de soya en Acuacultura. In: MENDOZA, CRUZ-SUÁREZ Y RICQUE (Eds.). SIMPOSIUM INTERNACIONAL DE NUTRICIÓN ACUÍCOLA, 2., 1994, Monterrey. Memórias... Monterrey: 1996. p.171-183.
TUCKER, J.W.; MACKINNON, M.R.; O'BRIEN, J.J. et al. Growth of juvenile Barramundi (Lates calcarifer) on dry feeds. The Progressive Fish-Culturist, v.50, p.81-85, 1988 .

VASCONCELOS FILHO, A.L.; AZEVEDO, S.B.; ALVES, M.L.C. Regime alimentar dos Camorins (Centropomus undecimalis (Block, 1792) e Centropomus parallelus Poey, 1860 do Canal de Santa Cruz (Pernambuco - Brasil). In: SIMPÓSIO BRASILEIRO DE AQUICULTURA, 1., 1978, Recife. Anais... Rio de Janeiro: Academia Brasileira de Ciências, 1980. p.175-184.

Recebido em: 30/05/01

Aceito em: 26/03/02 